\title{
Micro- and Nanostructure of Zn Whiskers and Their Coating
}

\author{
A. ETIENNE, ${ }^{1,5}$ E. CADEL,${ }^{1}$ A. LINA, ${ }^{2}$ L. CRETINON, ${ }^{3,4}$ and P. PAREIGE ${ }^{1,6}$ \\ 1.-Groupe de Physique des Matériaux, Université et INSA de Rouen, UMR CNRS 6634, Avenue \\ de l'Université BP 12, 76801 Saint Etienne du Rouvray Cedex, France. 2.-Department Material \\ and Mechanic Components, Corrosion Studies Laboratory, EDF R\&D, 77818 Moret sur Loing \\ Cedex, France. 3.-Department Electrical Equipment Laboratory, EDF R\&D, 77818 Moret sur \\ Loing Cedex, France. 4.-EDF SEPTEN, 69628 Villeurbanne Cedex, France. 5.-e-mail: \\ auriane.etienne@gmail.com. 6.—e-mail: philippe.pareige@univ-rouen.fr
}

To understand the mechanisms at the origin of whisker formation and growth, a Zn-electroplated steel prone to whiskering was studied. Several samples were prepared from different locations of the electroplated plate. Care was taken to extract samples at the root, in the nodule, or away from whiskers. Samples were characterized using electron backscattered diffraction (EBSD). Crystallographic data from EBSD show that recrystallized regions are present at the root of whiskers and in their nodules. These observations support whisker growth models based on recrystallization. In addition, atom probe tomography samples were prepared in the center of whiskers. The distribution of $\mathrm{Zn}$ atoms is almost homogeneous and no impurities are present in the whiskers.

Key words: Electroplating, whiskers, electron scattering diffraction, recrystallization, focused ion beam, atom probe tomography

\section{INTRODUCTION}

Since the 1940s and the discovery of short circuits caused by cadmium whiskers, ${ }^{1}$ a large number of studies have been focused on whiskering in metals. Indeed, the only way to minimize whisker growth, so that induced electrical or electronic disturbances are avoided, is to understand in detail the mechanisms at the origin of whiskering. It is known that whiskers grow spontaneously, at room temperature, from electroplates such as tin,${ }^{2-7}$ zinc, ${ }^{8-11}$ or cadmium coatings. Metallic whiskers show different morphologies: (i) whisker needles whose length can reach several millimeters, ${ }^{2}$ (ii) kinked whiskers that have sudden change in growth direction, and (iii) whiskers in the form of nodules from which needles can grow. Although whiskers have been studied for several decades, the mechanism of whisker growth is still not well understood.

As far as $\mathrm{Zn}$ is concerned, electroplated zinc coatings are usually used as an anticorrosive layer for low-alloy steels. These $\mathrm{Zn}$-coated steels are used for electronic components in automotive, aerospace,

(Received April 8, 2012; accepted June 19, 2012;

published online August 2, 2012) and energy industries, but also for support structures or raised-floor tiles in computer data centers. 8,10 The risk of electrical or electronic disturbances caused by $\mathrm{Zn}$ whiskers is significant, as shown, for example, by a National Aeronautics and Space Administration (NASA) data center report.

The most recent study on $\mathrm{Zn}$ whiskers ${ }^{10}$ presents $\mathrm{x}$-ray diffraction (XRD) and transmission electron microscopy (TEM) with energy-dispersive x-ray spectroscopy results. The authors show that the presence of $\mathrm{Fe}-\mathrm{Zn}$ intermetallics and $\mathrm{Zn}$ oxides plays a significant role in the presence of $\mathrm{Zn}$ whiskers by increasing the compressive stress on the $\mathrm{Zn}$ coating. Although their results are important for comprehension of whisker growth, the authors do not show any crystallographic information about whiskers and their coatings. To understand whisker formation and growth clearly, the micro- and nanostructure of the whiskers and their coatings must be characterized.

In the present work, an electroplated Zn coating prone to whiskers has been investigated using dualbeam scanning electron microscope-focused ion beam (SEM-FIB), electron backscattered diffraction (EBSD) and, for the first time, atom probe tomography (APT). The originality of this work lies in the 
fact that samples for EBSD were prepared at the root of the whisker using SEM-FIB. The samples for APT were cut off directly from Zn whiskers.

\section{EXPERIMENTAL PROCEDURES}

The studied material is a low-alloy carbon steel, namely S235, coated with Zn electroplating in 1982. The details of the electroplating process are not known. The thickness of the $\mathrm{Zn}$ coating is about $10 \mu \mathrm{m}$, lying on a $620-\mu \mathrm{m}$ steel substrate. The $\mathrm{Zn}$ coating is covered with a final chromate conversion coating of about $200 \mathrm{~nm}$ in thickness. The specimen investigated was used for several decades as an armor plate in an electronic device.

The residual stress and texture of the electroplated surface were measured by XRD using a Goniometer Siemens D500. XRD measurements of the residual stress by the $\sin ^{2} \Psi$ method indicate that the coating is under compressive stress of approximately $30 \pm 9 \mathrm{MPa}$. Internal stresses measured on a series of samples made using different plating baths were on the same order of magnitude. ${ }^{9}$

The $\mathrm{Zn}$ electroplated coating shows needle-like whiskers arising from nodules, as can be seen in Fig. 1. It should be noted that some whiskers do not have nodules and some nodules do not give rise to needle-like whiskers. Between 30 and 40 nodules or whiskers were observed per $\mathrm{mm}^{2}$ area. The diameter of whiskers varies between $1.5 \mu \mathrm{m}$ and $4 \mu \mathrm{m}$. The length of whiskers is up to $8 \mathrm{~mm}$.

Samples for EBSD were prepared using the liftout technique in a Zeiss Nvision 40 SMT dual-beam SEM-FIB following the procedure described in Ref. 12.

The EBSD experiments were carried out in the same dual-beam SEM-FIB using a $20-\mathrm{keV}$ electron beam with current of $1.5 \mathrm{nA}$. The EBSD step size was $50 \mathrm{~nm}$. EBSD patterns were acquired and indexed using an HKL (Oxford Instruments) Nordlys II detector and Channel 5 software. Pixel

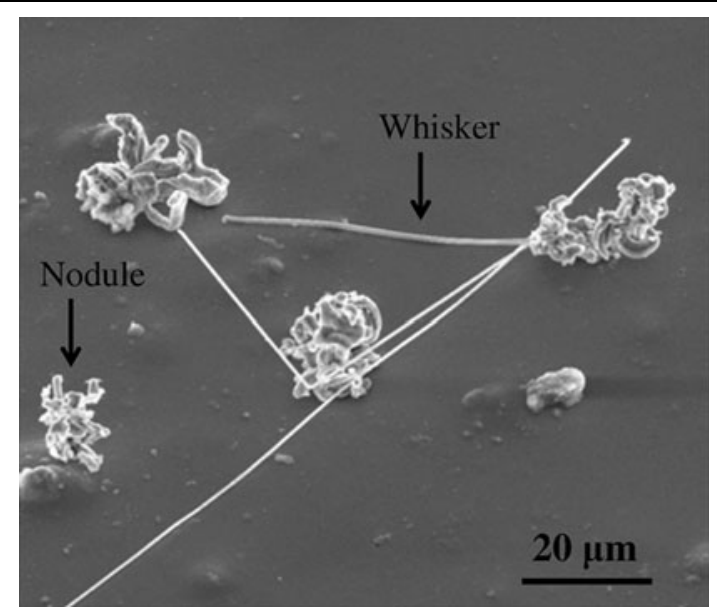

Fig. 1. Straight whiskers arising from nodules on the surface of the $\mathrm{Zn}$ electroplated coating. binning of $2 \times 2$ was applied for pattern acquisition. At the beginning of data treatment, noise reduction was applied. First, wild spikes (isolated points that have been incorrectly indexed) were extrapoled using copies of all neighboring points. Then, a zerosolution (diffraction patterns that could not be indexed) extrapolation was applied using six of the neighboring points.

Specimens were prepared from different locations in the $\mathrm{Zn}$ coating:

- Far from whiskers, in order to characterize the $\mathrm{Zn}$ coating

- At the root of whiskers without a nodule

- At the root of whiskers with a nodule

Atom probe experiments were performed using an energy-compensated wide-angle tomographic atom probe (ECoWATAP). This homemade atom probe is equipped with an advanced delay line positionsensitive detector. ${ }^{13}$ The mass resolution and detection limit are improved thanks to the energycompensated lens described in Refs. 14, 15. Analyses were performed at $80 \mathrm{~K}$ using electric pulses with pulse fraction of $20 \%$ and $30 \mathrm{kHz}$ repetition rate. Three-dimensional (3D) volumes were reconstructed and investigated using the data treatment software developed by the Groupe de Physique des Matériaux of the University of Rouen. Samples for atom probe investigation were also prepared using SEM-FIB. First, a tungsten tip with end radius of about $1 \mu \mathrm{m}$ was prepared by electropolishing. To obtain a flat end surface of about $2 \mu \mathrm{m}$, the end of the tip was then cut using a Ga-ion beam. Secondly, the micromanipulator probe was used to take a slice of about $10 \mu \mathrm{m}$ length of a whisker with diameter of about $2 \mu \mathrm{m}$. This slice was then attached using

(a)

(b)
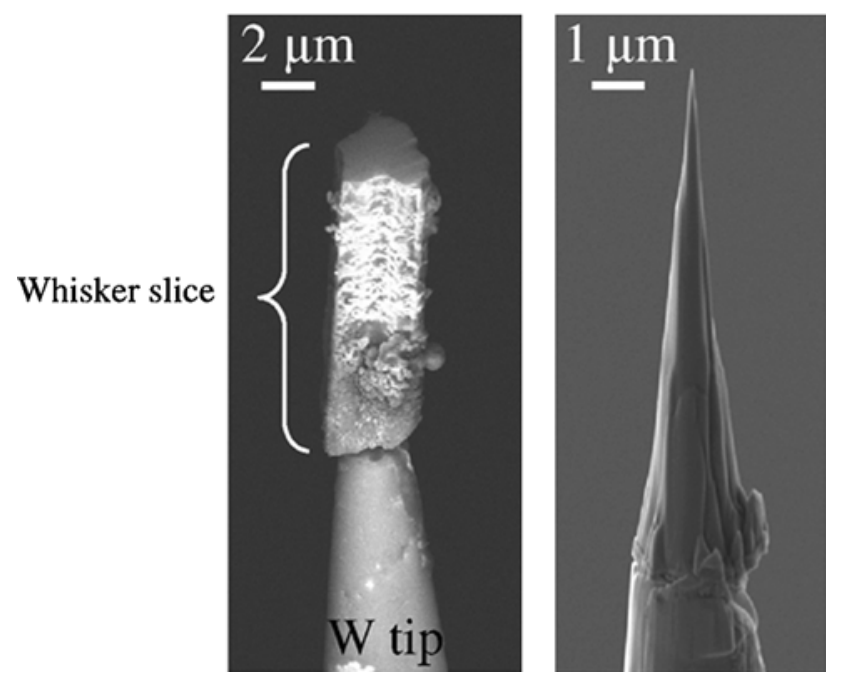

Fig. 2. Preparation of an atom probe tip from a whisker: (a) a slice of whisker is attached to a W tip, and (b) is milled as a tip needle using a Ga beam. 
platinum deposition at the top of the tungsten tip (Fig. 2a). The whisker slice was then annular Ga-ion milled into a sharp APT needle tip, as seen in Fig. 2b. The final milling was performed at Ga beam energy of $2 \mathrm{keV}$ with current of less than $150 \mathrm{pA}$.

\section{RESULTS AND DISCUSSION}

The microstructure of the $\mathrm{Zn}$ coating is clearly visible on the band contrast (BC) image obtained by EBSD on the specimen removed from the coating where there is no whisker (Fig. 3a). The $\mathrm{Zn}$ coating is composed of columnar grains with average length of $1.5 \mu \mathrm{m}$ and an average width of $310 \mathrm{~nm}$. The inverse pole figure images with respect to the $Y$-axis direction is depicted in Fig. 3b. It is shown from this figure that planes between $\{\overline{1} 2 \overline{1} 0\}$ (planes perpendicular to the $<2 \overline{1} \overline{1} 0>$ direction, in blue) and $\{10 \overline{1} 0\}$ (planes perpendicular to the $\langle 10 \overline{1} 0\rangle$ direction, in green) are parallel to the surface of the coating (Fig. 3c). This result is consistent with XRD measurements and with results of Lindborg et al. ${ }^{9}$

To understand the mechanisms at the origin of whisker formation and growth, samples for EBSD were prepared from different locations on the $\mathrm{Zn}$ electroplated plate.

First, one sample was prepared at the root of a whisker which did not grow from a nodule. The image of the whisker is depicted in Fig. 4a. The specimen blank was cut at the root of the whisker (Fig. 4b) and attached to a $\mathrm{Cu}$ grid (Fig. 4c). The microstructure at the root of the whisker using secondary-electron signal (Fig. 4c) looks complex. At the location where the whisker emerges from the coating, depletion of materials is clearly visible. Depleted regions at the surface around whiskers have already been observed by Boguslavsky and Bush $^{16}$ and suggest that a short-range diffusion mechanism of $\mathrm{Zn}$ atoms is involved during the growth of the whisker. More surprisingly, this sample shows the presence of cavities deep into the coating (up to about $9 \mu \mathrm{m}$ under the surface) and the presence of contrasts that differ from those observed for the $\mathrm{Zn}$ coating located at the root of the whisker. These regions with darker contrasts are highlighted in Fig. 4c. A preliminary study by TEM shows that the regions where the contrast is darker than in the $\mathrm{Zn}$ coating are enriched with $\mathrm{C}$ and $\mathrm{O}$. More TEM investigations are needed to conclude clearly on the nature of these regions.

As far as the cavities are concerned, it looks like there is a symmetric whisker root into the coating. The size of the cavities is between $1 \mu \mathrm{m}$ and $2 \mu \mathrm{m}$ in diameter. The length of the whisker is about $180 \mu \mathrm{m}$ and the diameter is $1.2 \mu \mathrm{m}$, which corresponds to a volume of about $200 \mu \mathrm{m}^{3}$. Considering that the whisker and the coating have the same hexagonal Zn structure, atoms coming from the cavities are not (a)

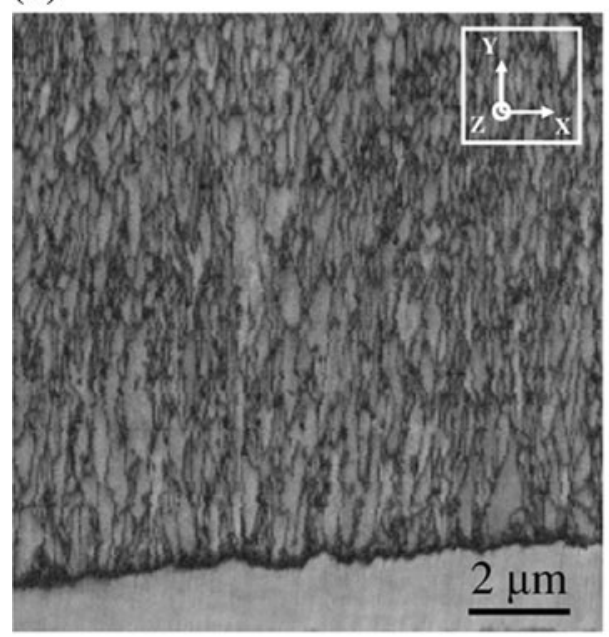

(c)

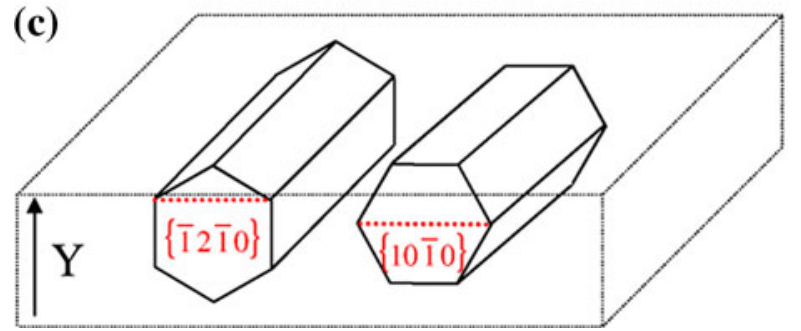

(b)

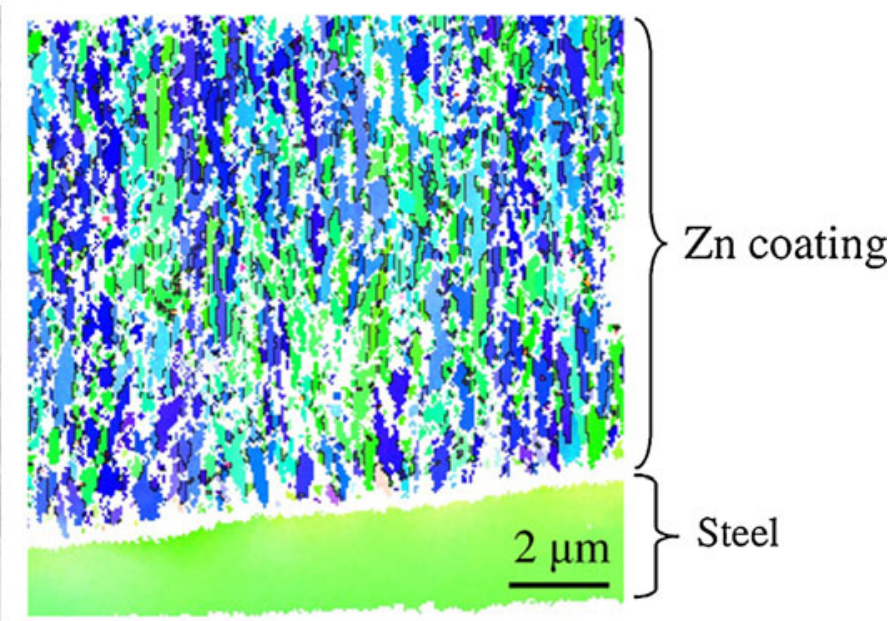

$\langle 0001\rangle$

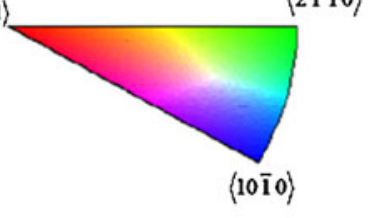

$\langle 2 \overline{1} \overline{1} 0\rangle$

Fig. 3. (a) Band contrast image, obtained by EBSD on the sample without whiskers, showing the grain structure of the coating. The steel substrate is visible at the bottom of the sample. (b) EBSD inverse pole figure of the Zn coating with respect to the $Y$-axis direction. (c) Schematic representation of the preferential crystallographic plane orientation in the $\mathrm{Zn}$ coating. 
(a)

(b)
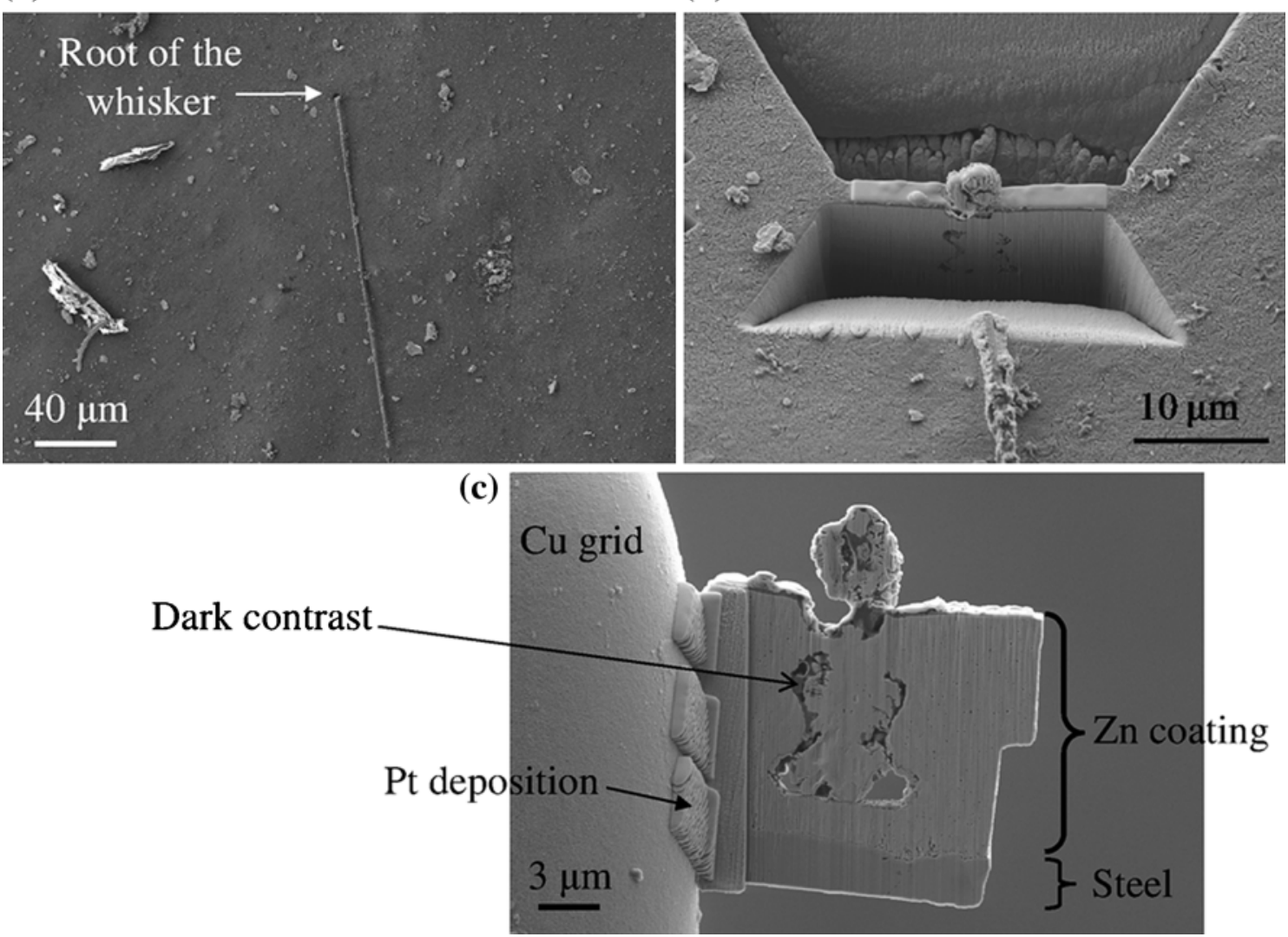

Fig. 4. (a) SEM top-view image of the whisker without nodule, (b) SEM image of the blank during milling around the base of the whisker, and (c) SEM side view of the milled blank attached to a Cu grid.

sufficient to create such a long whisker. As there is no other cavity around the whisker, this suggests that a long-range diffusion mechanism is also required for the growth of the whisker. No cavity was observed around or under other analyzed whiskers, confirming that a long-range diffusion mechanism is involved in the whisker growth. The presence of a long-range mechanism is coherent with results in the literature and has been accepted for a while by the community. 17,18

EBSD experiments performed on the sample show several differences between the grains at the root of the whisker and the grains into the $\mathrm{Zn}$ coating:

(i) The grains at the root of the whisker are equiaxed and larger (about $800 \mathrm{~nm}$ ) than the grains in the $\mathrm{Zn}$ coating $(1.24 \mu \mathrm{m}$ long and $295 \mathrm{~nm}$ wide).

(ii) The image quality factors of the grains at the root of the whisker are higher than the ones of grains into the $\mathrm{Zn}$ coating. This can be seen in the BC image (Fig. 5a). As the image quality factor can be related to the presence of defects and/or dislocations, this means that there are less defects and/or dislocations in grains at the root of the whisker than in grains into the coating. (iii) As depicted in Fig. 5b, the crystallographic orientation of the grains at the root differs from that of the coating grains. No preferential crystallographic orientation is observed at the root of the whisker.

(iv) The average misorientation angle between each pixel within each grain was calculated. If it is higher than the threshold angle $\theta_{\text {min }}$ defined by the user $\left(0.9^{\circ}\right.$ in this study), the grain is defined as a "deformed grain." Some other grains can be composed of subgrains. In this case, the average misorientation angle is under $\theta_{\text {min }}$ but the misorientation from subgrain to subgrain is higher than $\theta_{\text {min }}$. These grains are called "grains composed of subgrains." All the remaining grains are classified as "recrystallized grains." The calculation of the average misorientation angle shows that grains at the root of the whisker are less deformed (or recrystallized) than the grains into the Zn coating. Fifty percent of the grains are recrystallized at the root of the whisker, while only $12 \%$ of them are recrystallized in the $\mathrm{Zn}$ coating.

All these observations suggest that grains at the root of the whisker are recrystallized and are similar to those already described in a previous paper but on another whisker. ${ }^{12}$ 
(a)

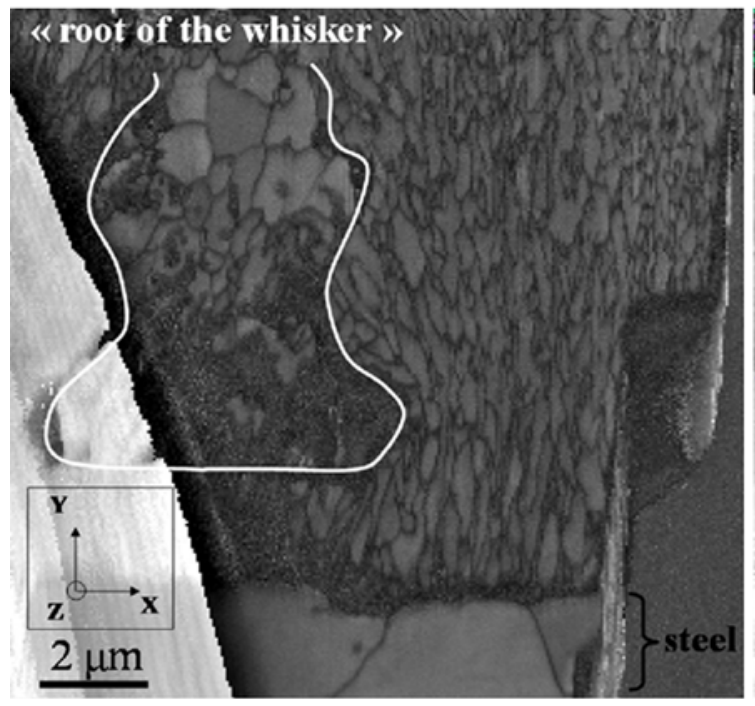

(b)

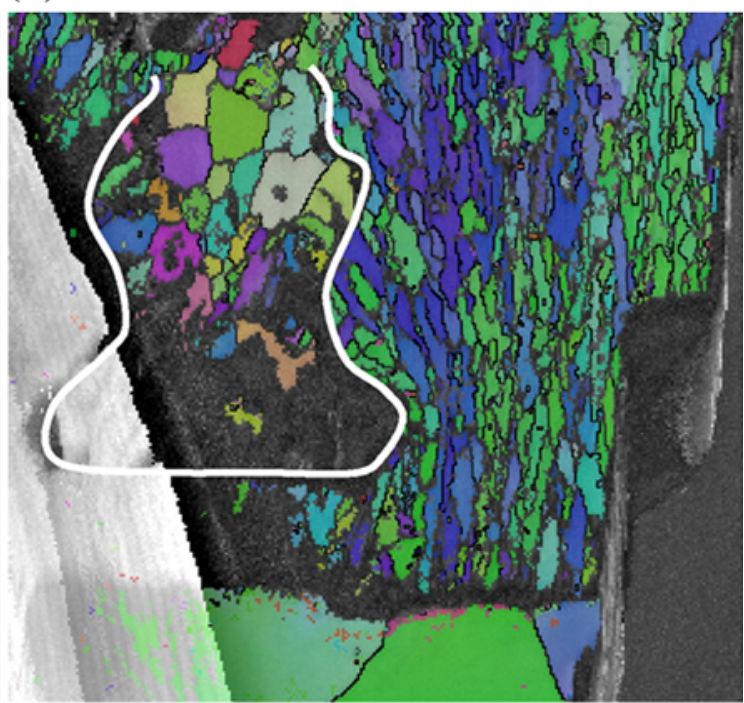

$\langle 0001\rangle$ $\langle 2 \overline{1} \overline{1} 0\rangle$

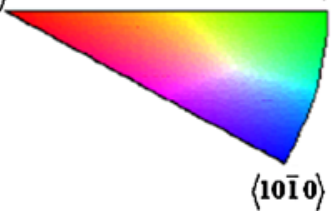

Fig. 5. (a) EBSD band contrast image of the sample prepared at the base of the whisker without a nodule. The "root of the whisker" is bounded by the white line. (b) Corresponding EBSD inverse pole figure with respect to the $Y$-axis direction.

Other samples were prepared from whiskers which grow from a nodule (Fig. 6a, b). The nodules are quite large, between $10 \mu \mathrm{m}$ and $20 \mu \mathrm{m}$ wide and long (Fig. 6c). EBSD shows that grains in the nodule are quite similar to grains observed at the root of the whisker. Indeed, in comparison with grains in the $\mathrm{Zn}$ coating, they:

(i) Are larger (diameter between $500 \mathrm{~nm}$ and $7.5 \mu \mathrm{m})$,

(ii) Are less deformed (7\% of the grains are considered as deformed in the nodule, while $73 \%$ of the grains are deformed in the coating),

(iii) Do not exhibit the same crystallographic orientation (no preferential crystallographic orientation of grains into nodules is observed).

Even if the mechanisms of whisker growth with or without a nodule are perhaps not the same, there are common phenomena between both because grains at the root and in the nodule of whiskers have the same characteristics.

Experimental results obtained in this study can be compared with the main models of whisker growth by recrystallization.

Starting from the fact that the $\mathrm{Zn}$ coatings prone to whiskers are composed of columnar grains under compressive stress, Smetana ${ }^{17}$ and Vianco and Rejent ${ }^{19}$ both suggested a model of whisker formation and growth based on recrystallization. This experimental work unambiguously demonstrates that, as suggested in both models, recrystallization plays a role in the whisker formation. However, none of these models explains all the observations.

In his model, Smetana ${ }^{17}$ explains how whisker formation relaxes the stress of the system. The first step is the formation of oblique grain boundaries during recrystallization of the coating. Due to the compressive stress into the coating, these oblique grain boundaries are subjected to a force which can cause their sliding. The whisker formation is the result of the grain boundary sliding. In addition to the grain boundary sliding, a diffusion process enables atoms to move from the coating to the base of the whisker. The diffusion is driven by a gradient of stress between the vertical grain boundaries and the oblique grain boundaries.

As already observed experimentally ${ }^{17}$ and predicted by the model, oblique grain boundaries are clearly visible at the root of the whisker. In the model, vertical grain boundaries play a key role in the diffusion process, however no vertical grain boundaries are experimentally observed below oblique grain boundaries. On the contrary, this model clearly explains the difference between whisker with and without a nodule. The phenomena are the same, but the presence of impurities cause lattice distortion and nodule growth.

Secondly, in the model described by Vianco et al. ${ }^{19}$ whisker formation and growth are induced by a cyclic dynamic recrystallization (DRX) mechanism. 
(a)

(b)
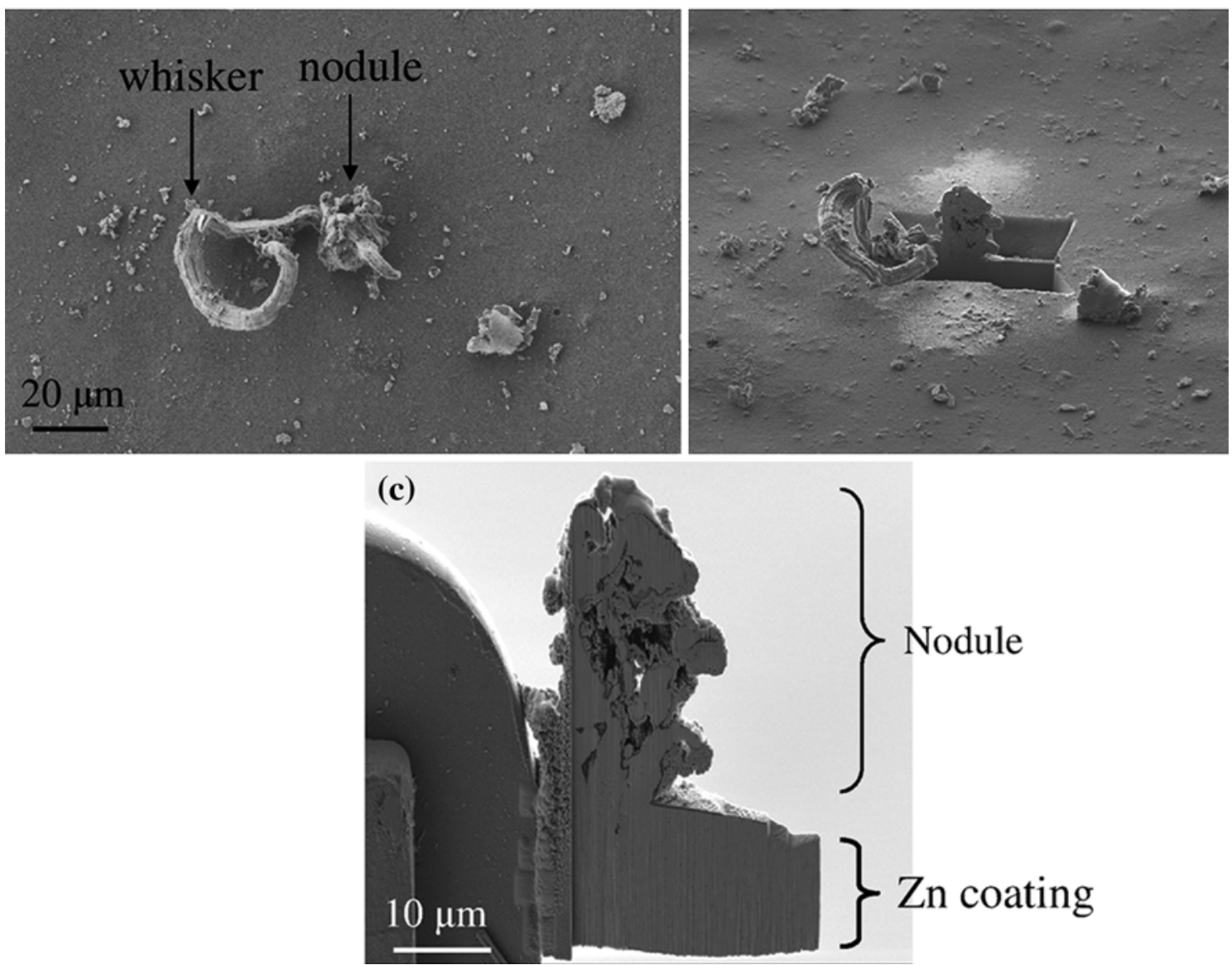

Fig. 6. (a) SEM top-view image of a whisker growing from a nodule and (b) the image of the milled blank during the sample preparation. (c) SEM side view of the milled blank attached to a Cu grid; the nodule and the $\mathrm{Zn}$ coating are visible.

Due to the compressive stress, dislocations are created and pile up at a vertical grain boundary. The storage of energy due to the dislocation pile-up results in the formation of a new grain free of defects at the vertical grain boundary. Once the new grain has reached its maximum size in the coating, it grows at the surface of the coating in the form of a whisker. In this study, it clearly appears that grain growth occurs at the root of the whisker. According to Vianco et al., one criterion for cyclic DRX is $D_{0}<2 D_{\mathrm{x}}$, where $D_{0}$ and $D_{\mathrm{x}}$ are, respectively, the initial grain size and the final grain size. The criterion is satisfied in the experimental results.

Some discrepancies appear between our experimental data and these model predictions. First, it is clear from the EBSD results that several grains have recrystallized, while only one is predicted by the models. Secondly, even though the whisker itself has not been analyzed by EBSD, there is no preferential orientation of the recrystallized grains as predicted by Vianco et al., such as $\{0001\}$ planes parallel to the surface.

A previous study ${ }^{10}$ indicates the key role of the formation of Fe-Zn intermetallics. To the authors' knowledge, no study considering the impurities in whiskers has been published yet. To check the presence and role of impurities in whiskers, a whisker was characterized using APT. A piece of a whisker was cut off by lift-out and prepared as a thin needle by FIB annular milling. It is noteworthy to specify that this is, to the authors' knowledge, the first atom probe analysis of a $\mathrm{Zn}$ whisker. More than 12 million atoms have been collected. The mass over charge spectrum obtained by APT is depicted in Fig. 7. $\mathrm{Zn}$ ions are clearly identified. The five isotopes of $\mathrm{Zn}$ ions (64 amu, $66 \mathrm{amu}, 67 \mathrm{amu}, 68 \mathrm{amu}$, and $70 \mathrm{amu}$ ) are detected in both $1+$ and $2+$ charge states. The measured isotopic abundances $(50.9 \%$, $26.5 \%, 3.9 \%, 18.1 \%$, and $0.6 \%$, respectively) are in good agreement with the theoretical values $(48.6 \%$, $27.9 \%, 4.1 \%, 18.8 \%$, and $0.6 \%$, respectively). $\mathrm{ZnH}$ molecular ions are also detected in both $1+$ and $2+$ charge states, representing $1.3 \pm 0.1$ at.\%. Note that the latter does not necessarily correspond to the form in which this element exists in the material, as $\mathrm{H}$ atoms can come from the atmosphere of the analysis chamber. A small amount $(0.004 \pm$ 0.002 at.\%) of $\mathrm{O}$ ions is also present in the mass spectrum. An ion peak was also detected at $28 \mathrm{amu}$, representing $0.03 \pm 0.01$ at.\%. Ions are homogeneously 


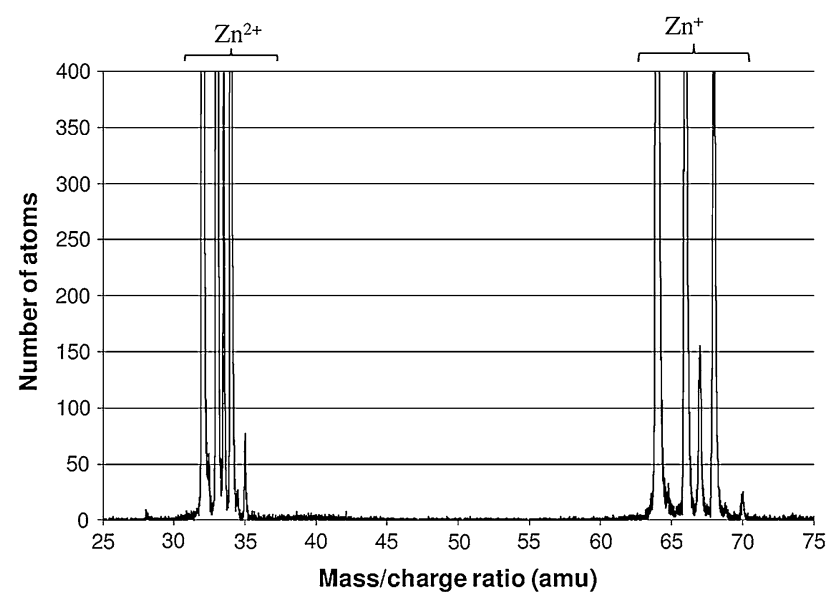

Fig. 7. Mass spectrum of a whisker obtained by APT.
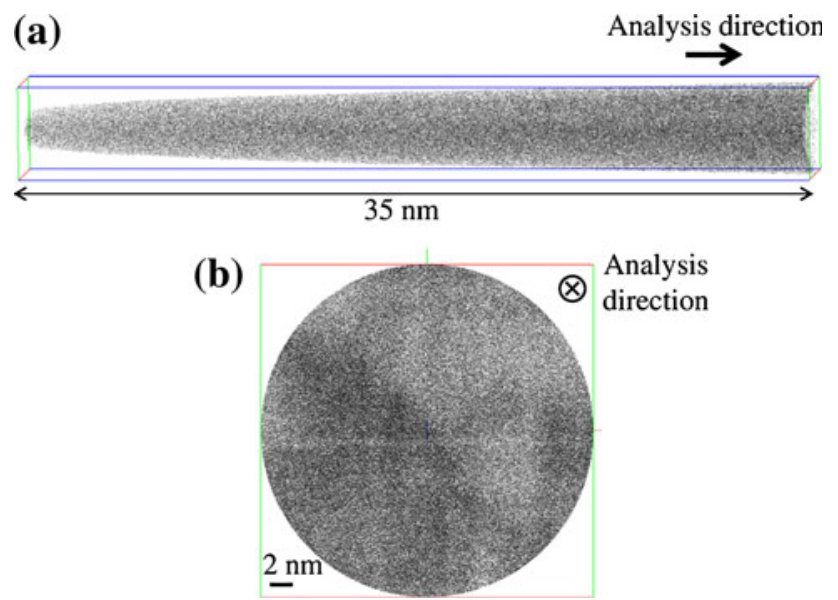

Fig. 8. Three-dimensional reconstruction of the volume analyzed by APT in a whisker. Only $5 \%$ of the $\mathrm{Zn}$ atoms are represented for clarity.

distributed in the volume. Considering the natural isotopic abundances, this peak does not correspond to either $\mathrm{Fe}^{2+}$ or $\mathrm{Si}^{1+}$ ions. As no $\mathrm{N}^{1+}$ ions are detected, it probably does not correspond to $\mathrm{N}_{2}^{1+}$ ions. It is important to note that, if $\mathrm{Fe}$ is present in the whisker, its concentration is lower that the detection limit, which is, for this particular case, estimated to be about 0.1 at.\%.

The reconstructed volume is depicted in Fig. 8a; only $\mathrm{Zn}$ ions are represented. The distribution of $\mathrm{Zn}$ atoms is quite homogeneous. The fact that the distribution of $\mathrm{Zn}$ atoms is not perfectly homogeneous, as can be seen in the two-dimensional (2D) projection image in Fig. $8 \mathrm{~b}$, is due to the difficulty in evaporating $\mathrm{Zn}$ atoms. The same kind of results was obtained on pure $\mathrm{Zn}$ metal.

This first atom probe analysis of a $\mathrm{Zn}$ whisker is promising and shows that the whiskers are probably free of $\mathrm{Fe}$ atoms. The next step will be to investigate the composition of whiskers at different locations (tip and root) and to characterize, using
APT, the Zn coating at the root of whiskers to highlight the presence of impurities or intermetallics.

\section{CONCLUSIONS}

Samples for EBSD were prepared from different locations of a Zn-electroplated plate prone to whiskering. The first sample was taken from the plate where no whisker had grown. The second one was prepared at the root of a whisker which did not present a nodule. The third one was prepared at the base of a whisker with a nodule.

EBSD analysis highlights different regions into the $\mathrm{Zn}$ coating prone to whiskers:

(i) The Zn coating with columnar grains and vertical grain boundaries. Grains within this region are oriented with planes between $\{\overline{1} 2 \overline{1} 0\}$ and $\{10 \overline{1} 0\}$ parallel to the surface of the coating. Most of the grains are classified as "deformed" grains.

(ii) The root region with larger grains than in the coating. Grains do not have the same crystallographic orientation as grains in the coating. Grains in this region have a higher quality factor than grains in the coating, and most of them are considered as recrystallized. An interesting observation was made at the root of the whisker without a nodule: the root of the whisker is surrounded by cavities.

(iii) The nodule, in which grains have the same characteristics as at the root of whiskers.

EBSD results show that grains at the root and in the nodule of whiskers are recrystallized. This is in agreement with recent whisker growth models that involve recrystallization for whisker formation.

In addition, for the first time, a slice of whisker was analyzed by APT. No Fe atoms were found in the whisker. The whisker is probably pure $\mathrm{Zn}$.

\section{ACKNOWLEDGMENTS}

This work was done within the framework of Carnot Institute Energy and Propulsion Systems (ESP) and in collaboration with the EDF R\&D Research Centre Les Renardières.

\section{REFERENCES}

1. H.L. Cobb, Mon. Rev. Am. Electroplat. Soc. 33, 28 (1946).

2. G.T. Galyon, IEEE Trans. Electron. Packag. Manuf. 28, 94 (2005).

3. G.T. Galyon and L. Palmer, IEEE Trans. Electron. Packag. Manuf. 28, 17 (2005).

4. E. Chason, N. Jadhav, W.L. Chan, L. Reinbold, and K.S. Kumar, Appl. Phys. Lett. 92, 171901 (2008).

5. S. Lal and T.D. Moyer, IEEE Trans. Electron. Packag. Manuf. 28, 63 (2005).

6. H.G. Smith and R.E. Rundle, J. Appl. Phys. 29, 679 (1958).

7. M.W. Barsoum, E.N. Hoffman, R.D. Doherty, S. Gupta, and A. Zavaliangos, Phys. Rev. Lett. 20, 206104 (2004).

8. J. Brusse and M. Sampson, IT Prof. IEEE Comput. Soc. 6, 43 (2004).

9. U. Lindborg, S. Ramsin, L. Lind, and L. Révay, Plating 61, 1111 (1974).

10. A. Baated, K.-S. Kim, and K. Suganuma, J. Mater. Res. 25, 2175 (2010). 
11. H.L. Reynolds and R. Hilty, IPC/JEDEC Lead Free North America Conference (Boston, 2004).

12. A. Etienne, E. Cadel, A. Lina, L. Cretinon, and P. Pareige, IEEE Trans. Compon. Packag. Manuf. Technol., in press (2012). doi:10.1109/TCPMT.2012.2203134.

13. G.D. Costa, F. Vurpillot, A. Bostel, M. Bouet, and B. Deconihout, Rev. Sci. Instrum. 76, 013304-1 (2005).

14. D. Blavette, A. Bostel, J.M. Sarrau, B. Deconihout, and A. Menand, Nature 363, 432 (1993).
15. E. Bémont, A. Bostel, M. Bouet, G. Da Costa, S. Chambreland, B. Deconihout, and K. Hono, Ultramicroscopy 95, 231 (2003).

16. I. Boguslavsky and P. Bush, APEX Conf. (Anaheim, CA, 2003).

17. J. Smetana, IEEE Trans. Electron. Packag. Manuf. 30, 11 (2007).

18. U. Lindborg, Acta Metall. 24, 181 (1976).

19. P.T. Vianco and J.A. Rejent, J. Electron. Mater. 38, 1815 (2009). 